\title{
"CAMPUS FREE" BASED ON SELF-REGULATED LEARNING AND EXAMPLES BASED CAMPUS TO INCREASE SELF-STUDY ABILITY AND LEARNING ACHIEVEMENT OF DISTANCE EDUCATION STUDENTS
}

\author{
Tetty Sufianty Zafar ${ }^{1}$, Usep Dayat ${ }^{2}$ \\ ${ }^{1}$ Ibn Khaldun University UIKA Bogor , ${ }_{2}^{2}$ Singaperbangsa University Karawang \\ Email: 1 tetty.sufiantyzafar@uika-bogor.ac.id ,2 fisip@unsika.ac.id
}

\begin{abstract}
The purpose of research is to download getahui whether psychological intervention, which is usually given in a way of learning that is given from a distance (online). Given psychological intervention aimed at enhancing the Self-Study Ability and Learning Achievement maha the student. This research is an experimental field study and was conducted to answer the two main hypotheses as follows: (1) intervention will significantly improve the ability of independent learning of first year distance education students, and (2) intervention will significantly improve the first achievement of distance education students year. In short, this research proves that psychological interventions that are usually used in face-to-face education can effectively be used in the context of distance education. Such findings indicate that interventions significantly increase students' awareness of the need for learning which leads to an increase in their independent learning abilities.
\end{abstract}

Keywords: independent learning, independent learning.

\section{INTRODUCTION}

The purpose of education in general is to produce people who are capable of intellectual independence. Intellectual independence which is the goal of education can be achieved through various modes of education, one of which is through distance education.

Distance education in Indonesia is one alternative mode of education which began to be implemented in 1955 with the establishment of a diploma program through correspondence to improve teacher competence (Belawati, 1995). In the field of tertiary education, distance education in Indonesia is held to expand access to tertiary institutions, especially overcoming constraints of absorptive capacity of senior high school graduates not accommodated in face-toface public tertiary education and giving opportunities for those who work to be able to follow the tertiary level (Setijadi, 1988). Viewed from the form of the implementation of education, distance education tends to be in the form of mass education .

The implementation of distance education has the main characteristic that is physical separation between instructor and student. The existence of physical separation leads to patterns of behavior of teachers and students who are different from their behavior patterns in face-to-face education (Haryono, 2001). In distance education, independence in learning becomes a demand for students who want to succeed, because students must act as instructors for themselves, especially in motivating themselves to learn learning material. The demand to be independent in learning is not an easy thing to do. Opinions of experts and research results shows the readiness of students to study with the distance education system, because they are accustomed to face-to-face education patterns (Darmayanti, 1993; Kadarko, 2000; Kasworm, 1992). The lack of ability to adapt to be independent in learning is one aspect that contributes to the low learning achievement in the first year of distance education students (Darmayanti, 1993; Indrawati, 1993). This condition occurs because independence is an individual characteristic factor that can influence the learning process and learning achievement (Belawati, 1997; Syamsudin, 1984).

Based on the condition of distance education students as described above, there seems to be a gap between the ideal conditions of distance education students who are supposed to be 
independent in learning, with real conditions based on the opinions and results of research experts who show a lack of student independence in learning. The existence of these gaps is an initial problem that is expected to be assessed whether these gaps can be minimized through interventions.

Moore (1986), Paul (1990), Simpson (2000), Stoane (1985) and Wright (1989) stated the importance of helping students of distance education institutions to develop their own learning abilities. Improving the ability to learn independently can be done in various ways. In the field of Educational Psychology, improvement of learning skills can be done through the concept of selfregulated learning (Bandura, 1986) . However, various models to improve independent learning ability are generally developed by experts from countries outside Indonesia. The learning capacity development model is not necessarily in accordance with Indonesian culture.

In addition to paying attention to culture, the intervention program also needs to consider the exemplary factor because someone who is given the intervention is expected to imitate the exemplary figure. Exemplary in Indonesian culture is reflected in paternalistic culture, so that the concept of "role models" appears. In general, exemplary figures are considered to be older, higher degrees or figures that are considered more than those who consider these figures as role models.

Based on various opinions and research findings of experts, it appears that intervention is needed in the development of independent learning abilities. Interventions can be carried out in various ways that can be adapted to Indonesian culture.

This research was conducted with the aim of testing whether intervention was needed and could be done to develop independent learning abilities and student achievement. Psychological intervention can be carried out in various ways that are appropriate to the context of distance education and Indonesian culture. More specifically, this study aims to provide a deep understanding of the ability of independent learning to distance education students in Indonesia. The main objective of this study is to examine the effectiveness of the intervention program of selfregulated learning skills and modeling or " modeling " in improving independent learning abilities which then indirectly will increase the learning achievement of distance education students.

This research is expected to be able to contribute to increasing the learning achievement of distance education students through increasing their independent learning abilities. This research is also expected to contribute knowledge in the field of educational psychology, especially in the field of psychology of distance education in Indonesia which is still very limited. The next benefit of this research is that this research is expected to be able to contribute knowledge in the field of counseling psychology for distance education, because the characteristics of distance education students are different from face to face education students.

The concepts used in this study include distance education, self-directed learning, selfregulated learning and modeling . The following are discussed about these concepts.

\section{Distance Education}

Distance education is one form of education that has different learning delivery characteristics than face-to-face education, namely the existence of physical separation between instructors and students (Moore \& Kearsley, 1996; Keegan, 1990). In distance education, students are required to be more able to learn independently compared to students face to face.

According to Moore (1990), in distance education there is a "transactional distance" or dialogue transactions between teachers and students through various ways or media, where the media is an implementation of the learning structure. The dialogue on distance education involves three parties, namely students, instructors and learning structures. The role of instructors (external educators) in distance education tends to be one source of knowledge learned by students (Bagnall, 1989). In addition to the role of instructors, students can become instructors for themselves ( internal educators ) who direct or organize themselves to interact with teachers and with the learning structures provided in distance education (Bagnall, 1989). 


\section{Self-Directed Learning in Distance Education}

The phenomenon of independence in learning ( self-direction in learning) in distance education is explained in a variety of literature using labels or terms from the concept of independent learning or self -directed learning (Candy, 1991; Hiemstra, 1998; Knowles, 1975; Moore, 1983 1986, Moore Kearsley, 1996; Simpson, 2000). In this study, self-learning ability possessed by the learner is defined as the ability to take the initiative to organize ( regulate), manage and control the process of learning to cope with various problems in learning by using a variety of alternative or learning strategies (Jarvis, 1990). The key word for independent learning is the existence of "initiative" or "proactive" attitude from someone to manage their learning (Hiemstra, 1998; Knowles, 1975). This definition explains that independent learning is a type of learning that is distinguished from learning directed by others or teacher-directed learning. In teacher-directed learning, students are more reactive in the learning process directed by the teacher (Darmayanti, 1993). In the context of distance education, independent learners have the ability to learn in conditions that require themselves to learn without depending entirely on the instructor. According to Candy (1991), there are four dimensions of independent learning, namely a) selfautonomy; b) self-management; c) independent learning needs; d) student control of learning .

Increasing the ability of independent learning through increased learning skills in the field of Educational Psychology is the application of Cognitive Learning theory (Bandura, 1986; Woolfolk, 1993), mainly related to the concept of self-regulated learning (Zimmerman \& Schunk, 1989). Bandura (1986) suggests that the development of self-regulatory skills is one way to increase selfdirectedness. Therefore, in this study, the concept of self-regulated learning (SRL) is used as a basis for developing programs to improve the ability to learn independently from distance education students.

\section{Self-Regulated Learning}

Self-regulation theories focus on how students move, change, and maintain learning activities both individually and in their social environment, in informal and formal instructional contexts (Zimmerman \& Schunk, 1989). Ajisuksmo (1996) makes it clear that self-regulated learning occurs when students systematically direct their behavior and cognition towards the achievement of learning goals. Students who have the ability to self-regulated learning will show the characteristics of having goals, are strategic and persistent in learning (Purdie, Hattie, \& Douglas (1996).

Self-regulated learning is an important aspect of student academic achievement (Hofer, Yu, \& Pintrich, 1998; Pintrich \& De Groot, 1990). The results of various previous studies conducted by Pintrich and De Groot (1990), Schunk and Zimmerman (1994), Zimmerman and Martinez-Pons (in Wolters, 1998), revealed that students who were more aware and exercised greater control over cognitive processes tended to more successful learning outcomes.

Zimmerman (1998) further explained that the cycle of self-regulated learning can be grouped into three stages, namely stages: (1) initial thinking; (2) control over the implementation or will; (3) Self-reflection stage. Vermunt (1998) states that the learning component in self-regulated learning consists of four, namely: (1) processing skills, also called cognitive skills ; (2) selfregulation skills ; (3) learning concepts ; (4) learning orientation.

The topics of self-regulation are very closely related to motivation (Pintrich \& Schunk; 1996). Students who are motivated to achieve goals will involve self-regulation activities that they believe can help them (eg memorizing the material being studied, clarifying unclear information). Instead, self-regulation enhances learning, and perceptions of greater competence to continue motivation and self-regulation to achieve new goals (Schunk, 1991 in Pintrich \& Schunk, 1996). Theoretically, students who have the ability to self-regulation actively manage aspects of motivation that involve their willingness to learn. According Corno (in Wolters, 1998), will or v olition describes the process involved to maintain that intention (intention) or goals are met, and distinguished from the motivation that only alludes to the initial process that was created from the intent or purpose. Increased motivation is assumed to increase the willingness to learn which will 
direct one's independent learning ability and then help the person to excel. In this study, increasing self-regulated learning skills is expected to bring up learning motivation which will then direct one's will to become self-regulated learners who are able to be independent in their learning.

\section{Modeling}

Nearly everything that can complement self-regulatory skills depends on a variety of techniques, including modeling (Pressley \& Woloshyn in Hofer, Yu, \& Pintrich, 1998; Zimmerman, 1998). Exemplary figures can be a motivating component of an intervention program based on selfregulated learning (Hofer, Yu, \& Pintrich, 1998).

Figures that are generally modeled as models are people who are considered "more" by those who will imitate the model figures. According to Pintrich and Schunk (1996), the characteristics of the model that are considered important in influencing role models are competence, perceived similarity, credibility, and enthusiasm .

In the field of distance education, exemplary teaching is difficult. In general, the condition of exemplary teaching figures cannot occur in distance education. This is the reason for using students as exemplary figures in this study, namely outstanding students who are in accordance with the components of competency, equality, credibility, and enthusiasm. Through exemplary figures, it is expected that students can know other people's experiences in learning and then can get ideas or ideas for learning for themselves.

Based on the study of various theoretical concepts about independent learning abilities, selfregulated learning skills, motivation, example and learning achievement, two interventions were developed, namely learning skills interventions and exemplary interventions. Learning skills interventions are developed in one of the four components of self-regulated learning proposed by Vermunt (1998), namely self-regulation skills . Meanwhile, the contents of the program are learning management skills which include setting goals ( goal setting) and learning strategies related to setting these goals. The contents of the program are developed using themes so that they are easy to remember and understand. To strengthen the "willingness" of learning or motivation on interventions based on the components of self-regulation skills, this study also provides an intervention figure model that uses the ability to learn independently.

In accordance with the characteristics of distance education, the provision of interventions is carried out using the media as a liaison between teachers and students. For the field of Psychology in Indonesia, the use of media for interventions is still rarely used.

This study uses a field experiment approach ( field experiment ), with a true experimental design ( true experiment) or the actual experimental design because it meets all the experimental requirements, namely the treatment or intervention, the experimental group and the control group, pretest and posttest, and random assignment ( Christensen, 2001; Faisal, 1989; Liebert \& Liebert, 1995; Sukadji, 2000). More specifically, the design used is called " Randomized Control-Group Pretest-Postest Design" (Liebert \& Liebert, 1995).

The general hypotheses of this study are as follows: (1) There is a difference in the increase of students' independent learning abilities of the first experimental group, the second experimental group, the third experimental group and the control group; (2) There is a difference in students' achievement in the first experimental group, the second experimental group, the third experimental group and the control group.

The independent variable of this study is an intervention given to distance education students, consisting of three interventions, namely: (1) exemplary intervention; (2) intervention of Self-Regulated Learning (SRL) skills ; (3) exemplary intervention and SRL skills. The dependent variable in this study is the ability of students to study independently and student achievement.

The operational definitions for the variables in this study are as follows :

1. Exemplary intervention is the first independent variable (Intervention 1) in this study. Exemplary material contains stories about exemplary figures whose role is to motivate and reinforce the formation of new behaviors from imitating subjects. Interventions are given through sending printed material to research subjects. 
2. Self-Regulated Learning (SRL) Skills Intervention (Intervention 2) is the second independent variable in this study. SRL Skills material contains the concepts of management / learning arrangements and preparation of learning plans or learning goals / targets ( goal setting). Interventions are given through sending printed material to research subjects.

3. The combined intervention of exemplary and SRL Skills (Intervention 3) is the third independent variable in this study. Intervention material contains exemplary figures and SRL skills, which are provided through the combined delivery of the two printed materials to the research subjects.

4. Independent learning ability is the first dependent variable in this study. Self- study ability was revealed through the Self-Directed Learning Readiness Scale (SDLRS) version of the self-study questionnaire by researchers. The analysis was carried out on the difference in the score ( gained score ) of total independent learning abilities at the pretest and posttest stages.

5. Learning achievement is the result of learning or the results of academic activities carried out by students and is the second dependent variable. The learning achievement variable is expressed through the Performance Index indicator per semester (IP) obtained by students in the semester when the research is carried out, namely IP in semester 2004.1 and 2004.2. Analysis was carried out on the difference in gained scores of semester 2004.1 (pretest) and semester 2004.2 (posttest).

6. Intervention evaluation is a manipulation check of SRL skills and examples exemplified by the Intervention Evaluation Questionnaire. This variable is not involved in the hypothesis but serves to ensure that the conditions being manipulated are indeed perceived by the subjects as being desired by the researcher.

The research was conducted in two stages. The first stage is the pre-experimental stage and the next stage is the implementation of the experiment. In the pre-experimental stage, they are carried out: (1) initial procedures (development of the term Self-Regulated Learning skills and selection of exemplary story figures), (2) development of experimental material content, and (3) evaluation of experimental material.

The pre-evaluation method of experimental material is a qualitative approach, namely by indepth interviews and observations of five research subjects from the Public Administration Study Program (PS ADPU) at the Open University (UT). The results of the pre-evaluation qualitative analysis of this experimental material show that the two experimental materials developed in this study are worthy of being used as experimental material. The two materials are "SMART Learning Strategies in Distance Education" which is an experimental material for Self-Regulated Learning skills , and "Behind the Open University Toga" which is an exemplary experimental material.

In the implementation of the pretest stage experiment, the experimental material and the questionnaire were sent to the research subjects by post at the beginning of the second semester of 2004. At the end of the 2004 semester, the posttest questionnaire was sent back to the same research subject.

\section{RESEARCH METHODS}

This research uses a qualitative descriptive approach, and the type of research used is library research, which is collecting data or scientific papers relating to research objects or collecting data that is library. Or study carried out to solve a problem which is basically based on critical and indepth study of relevant library materials According to M. Nazir library study is a data collection technique by conducting a study of the review of books, literature, records and reports that have to do with the problem being solved.

Furthermore, M Nazir added that library research is an important step, where after a researcher determines the research topic, the next step is to conduct a study related to the research topic theory. In describing the theory, the researcher will collect as much information as possible from the relevant literature. Literature sources can be obtained from books, journals, magazines, research results and other suitable sources. If you have obtained relevant literature, then it is compiled regularly to be used in research. Therefore the literature study covers general processes such as 
identifying theories systematically, finding libraries and analyzing documents that contain information related to research topics., M. Nazir, "Research Methods" (Jakarta: Ghalia Indonesia)

\section{RESULTS AND DISCUSSION}

\section{Intervention and Independent Learning Ability}

The interventions developed in this study, especially SRL skills interventions, proved to be effective in increasing independent learning abilities. Statistically, the role of interventions in increasing the ability of independent learning is $9 \%$. Thus, the results of this study reject the notion that states that intervention is not needed to improve the ability to learn independently (Dittman in Candy, 1991). The findings of this study prove that interventions are needed to improve students' independent learning abilities, especially interventions of learning skills (Bandura, 1986; Belawati, 1997; Candy, 1991; Moore, 1986; Paul, 1990; Pintrinch \& Groot, 1998; Stoane, 1885; Wright , 1989; Zimmerman, 1998).

The findings of this study indicate that psychological theories can be useful in the field of distance education especially to overcome learning problems and improve student learning achievement. Psychological interventions that are generally given face-to-face can also be given remotely. This condition is at the same time the originality of this study, namely the provision of psychological interventions through remote media. The findings in this study also contribute to the development of a more specific discipline of Educational Psychology, namely the field of Distance Education Psychology with the specificity of the discussion being humans or individuals involved in distance education.

In the follow-up analysis of intervention data, especially on the components of independent learning abilities, it was found that the components of learning needs increased compared to the other components of independent learning abilities (components of self-regulation, self-autonomy and student control). Statistically, the contribution of the role of intervention to increasing learning needs is $12 \%$. The existence of SRL skill interventions helps students who were previously unaware of their learning needs because they do not yet know what they will face in studying at distance education colleges become more aware of their learning needs. In addition, the increasing learning needs in this study are positive conditions as explained by Huitt (1999) and Zimmerman (1998).

In addition, interesting findings actually emerge when exemplary interventions are combined with SRL skills interventions. The effectiveness of SRL skill interventions when combined with exemplary interventions still significantly enhances the components of these learning needs. However, these interventions are not strong enough to improve overall student independent learning abilities.

More specifically, the research findings show that role models are not proven to be effective in increasing the ability of independent learning for first year students. This is likely because the first-year students are still in the adjustment phase, so that modeling without direction is not enough to help students improve their learning abilities independently. Another possibility is the role of exemplary figures in motivating someone to not be able to stand alone, but needs to be followed by instructions on how to learn or how to do something practical and easily understood by subjects who are expected to emulate exemplary figures.

Intervention and Learning Achievement. The interventions developed in this study were not proven to be able to improve the learning achievement of distance education students. Markum (1998) explains that according to Weiner's causal attributional theory, there are four factors that influence a person's success or failure, namely: ability, business magnitude, task difficulty and luck. These four factors can be grouped into internal factors and external factors. This explanation shows the many factors that affect student learning achievement.

The results of this study indicate that the effect of intervention on increasing the ability to learn independently is equal to 9\%. Meanwhile the results of Darmayanti (1993) and Islam (2000) showed that the ability to learn independently only affected learning achievement around $6 \%-16 \%$. In addition, the interventions provided in this study are short-term interventions, while on the other 
hand the adjustment period for first-year students in distance education is not over. The first year is still a year of adjustment for students who still do not know the right way to study in distance education, so they have not been able to achieve optimal learning achievement. These conditions indicate the small effect of short-term interventions on learning achievement.

Provision of intervention needs to be done in stages to be able to improve student learning achievement (Pressley and Woloshyn in Hofer, Yu, \& Pintrich, 1998). Interventions on learning achievement need to be considered to be continued as long-term interventions gradually as suggested by Grow (1996) in order to influence learning achievement.

This study has limitations that need to be a separate note, namely as follows :

1. This research is a research for the development of Educational Psychology theory which is applied to distance education. This research is an experimental research field ( field experiment ) with a variation of the experimental intervention in the form of material and a questionnaire by mail or postal delivery. The method of collecting data by mail or post is one of the limitations of this study, because the control over the return rate of the questionnaire is not optimal.

2. Another limitation is the lack of control over the courses taken by students in this study. Learning achievement tends to be seen from the achievement index per semester which involves a number of courses. This study also cannot control the number of courses taken by research subjects.

3. In this study there is no control over the variables of the institution, such as administrative / academic services from the institution that may influence learning achievement. In the next research, it is expected that the limitations of this study can be improved through improvements to services to students and through statistical control on the design of data analysis.

4. This research is a short-term intervention study (about 4 months) and the possibility of a research period is one of the limitations of research in improving learning achievement.

These researchers found that specifically developed psychological interventions proved effective in increasing independent learning abilities, although they were not proven effective in increasing the learning achievements of first-year distance education students. More specifically, the results of the analysis show that: (1) the intervention of Self-Regulated Learning skills has proven to be effective in improving the independent learning abilities of first-year students of distance education; (2) exemplary interventions were not proven effective in increasing the ability of independent learning of first year students of distance education; (3) a combination of interventions has not been proven effective in increasing the ability to learn independently as well as student learning achievements in first year distance education; (4) the intervention of SelfRegulated Learning skills has proven effective in increasing the components of learning needs, but has not been proven effective in improving other components of self-regulated ; (5) combined interventions have been proven effective in increasing components of learning needs.

\section{CONCLUSION}

Based on the results of the study, the following theoretical suggestions are as follows :

1. This research only involved one study program at a distance education institution, because it was conducted in the framework of testing a theoretical model. This research is recommended to be carried out in other study programs as a comparison and it is hoped that through meta-analysis it can be examined its external validity.

2. For further research a long-term study is recommended. First year student data in this study can continue to be considered and further investigated as they enter the following year. If possible until they finish their study in distance education. The research on self-regulated learning skills in this study can be continued with the research on the development of intervention material on other components such as the skills to process learning materials, the skills to manage stress during learning and various other metacognitive skills.Exemplary research in this study can be continued by examining the role models of exemplary figures of people who are well known or 
known by the wider community. The role of exemplary figures of famous people may be more influential compared to figures that are less well known by students.

\section{SUGGESTION}

The results of this study also provide implications for the application of research results in daily life as follows :

1. The role of distance education institutions is needed in the first year to help students through the transition period from the dependency stage to the stage of interest or interest in distance learning activities, which then helps them to be more involved and subsequently develop independent learning abilities.

2. For distance education institutions, the results of this study are contributions of Psychology thinking to design a variety of first-year student orientation learning activities and learning assistance activities in the following year.

3. With the development of technology, the interventions developed in this study can be adopted by remote institutions to be developed through Internet network technology. Thus, there will be more students who can access learning assistance such as interventions in this study.

4. For those who are engaged in community empowerment which generally involve adult individuals, this research material can be used for training to increase independence because the ability to learn independently is one step in improving the quality of individual independence. The use of this material for community empowerment can be combined through distance education, because distance education is mass education that enables the development of large numbers of human resources and is able to reach areas in Indonesia which are spread across various islands.

\section{REFERENCE}

Ajisuksmo, CRP (1996). Self-regulated learning in Indonesian higher education . Doctoral thesis, Tilburg University. Jakarta: Atma Jaya Research Center.

Bagnall, RG (1989). Educational distance from the perspective of self-direction: An analysis. Open Learning, 4 (1), 21-26.

Bandura, A. (1986). Social foundations of thought and action: A social cognitive theory. Englewood

Cliffs, NJ: Prentice-Hall, Inc.

Belawati, T. (1995). Increasing persistence in Indonesian post-secondary distance education .

Unpublished doctoral dissertation, University of British Columbia, Vancouver, BC.

Belawati, T. (1997). Understanding and increasing student persistence in distance education: A case of Indonesia. Journal of Indonesian Studies, 7 (1), 29-46.

Candy, PC (1991). Self-direction for lifelong learning: A comprehensive guide to theory and practice . San Francisco: Jossey-Bass Publishers.

Christensen, LB (2001). Experimental Methodology (8th ed). Boston: Allyn \& Bacon. Darmayanti, T. (1993). Readiness for self-directed learning and achievement of the students of

The Open University (The Indonesian Open Learning University) . Unpublished master's thesis , University of Victoria, Victoria, BC.

Darmayanti, T. (2001). Self-directed learning readiness scale: Adaptation of independent learning research instruments. Journal of Open and Distance Education, 2 (2), 126 - 136.

Faisal, S. (1989). Social research formats . Jakarta: PT RajaGrafindo Persada.

Grow, GO (1996). Teaching learners to be self-directed. Adult Education Quarterly, 41 (3), 125149. Guglielmino, LM (1978). Development of the self-directed learning readiness scale (Doctoral

dissertation University of Georgia, 1977). Dissertation Abstracts International, 38, 6467-A. Haryono, A. (2001). Independent learning: Concepts and their application in open / distance education and training systems. Journal of Open and Distance Education, 2 (2), 137 - 161. 
Hiemstra, R. (1998). Self-advocacy and self-directed learning: A potential confluence for enhanced

personal empowerment. Paper presented at SUNY Empire State College Conference, Rochester, New York. Taken September 12, 2003, from http://home.twcny.rr.com/hiemstra/advocacy.html

Hofer, BK, Yu, SL, \& Pintrich, PR (1998). Teaching college students to be self-regulated learners. In DH Schunk., \& Zimmerman, BJ (Eds.). Self-regulated learning: From teaching to selfreflective practice . New York: The Guilford Press.

Huitt, W. (1999). Conation as an important factor of mind. Taken on March 30, 2001, from http://chiron.valdosta.edu/whuitt/col/regsys/conation.html.

Indrawati, E. (1993). Attrition and completion rates at the Indonesian Open University . Unpublished master's thesis, University of Victoria, Victoria, BC.

Islam, S. (2000). Learning achievement, readiness for independent learning and student selfconcept in open and distance education systems : A correlational study at Open University (1997). Unpublished master's thesis, Jakarta State University Postgraduate Program, Jakarta.

Jarvis, P. (1990). Self-directed learning and theory of adult education. In HB Long., \& Associates. Advances in research and practice in self-directed learning. Oklahoma: Oklahoma Researc Center for Continuing Professionals and Higher Education of the University of Oklahoma.

Kadarko, W. (2000). The ability to learn independently and the psychosocial factors that influence it: The Case of Open University. Journal of Open and Distance Education, 1 (1) , 27-41.

Kasworm, C. (1992). The development of adult learner autonomy and self-directedness in distance education. In the Conference Abstracts: Distance education for the twenty-first century. Conference held at the meeting of the International Council for Distance Education, Nonthaburi-Thailand.

Keegan, D. (1986, 1990). Foundations of distance education (2nd ed). London: Routledge.

Kerlinger, FN, \& Lee, HB (2000). Foundations of behavioral research (4th ed). Singapore:

Knowles, MS (1975). Self-directed learning: A guide for learners and teachers . Chicago: Follett Publishing Company.

Liebert, RM, \& Liebert, LL (1995). Science and behavior: An introduction to methods of

psychological research (4th ed.). New Jersey: Prentice-Hall, Inc.

Markum, E. (1998). The nature of Indonesia's human resources supporting development: A study of the prerequisite traits, family and school backgrounds of high-achieving individuals. Unpublished doctoral dissertation, Postgraduate Program, University of Indonesia, Jakarta.

Montgomery, DC (1991). Design and analysis of experiments (3rd ed). New York: John Wiley \& Sons.

Moore, MB (1983). Self-directed learning and distance educations . ZIPP Papiere 48. Fern Universitat. Hagen (West Germany). ERIC Document Reproduction Service No. ED 265 $825)$

Moore, MB (1986). Self-directed learning and distance education. Journal of distance education, 1 (1) . 7-24.

Moore, MB (1990). Recent contributions to the theory of distance education. Open Learning, 5 (3). $10-15$

Moore, MG, \& Kearsley, G. (1996). Distance education: A systems view. Belmont, Calilfornia: Wadsworth Publishing Company.

Nazir, Moh. (2013). Metode Penelitian. Bogor: Ghalia Indonesia.

Paul, R. (1990). Towards a new measure of success: Developing independent learners. Open Learning, 5 (1), 31-38.

Pintrich, PR, \& De Groot, EV (1990). Motivational and self-regulated learning components of classroom academic performance. Journal of Educational Psychology, 82 (1), 33-40.

Pintrich, PR, \& Schunk, DH (1996). Motivation in education: Theory, research and application .

New Jersey: Prentice-Hal, Inc. 
Purdie, N., Hattie, J., \& Douglas, G. (1996). Student conception of learning and their use of selfregulated learning strategies: A cross-cultural comparison. Journal of Educational Psychology, 88 (1), 87-100.

Schunk, DH, \& Zimmerman, BJ (Eds.). (1994). Self-regulated learning: From teaching to selfreflective practice. New York: The Guilford Press.

Setijadi. (1988). Indonesia: Open University. Prospects , 8 (2), 189-197.

Simpson, O. (2000). Supporting students in open and distance learning . London: Kogan Page. Stoane, C. (1985) Study skills for home learners. Programmed Learning \& Educational Technology, 22(4), 347-350.

Sukadji, S. (2000). Prepare and evaluate research reports . Jakarta: University of Indonesia Publisher (UI-Press).

Syamsuddin, A. (1984). Educational psychology . Bandung: Institute of Teacher Training and Education. Vermunt, JD (1998). The regulation of constructive learning processes. British Journal of

Educational Psychology, 68, 149-171.

Wolters, CA (1998). Self-regulated learning and college students' regulation of motivation. Journal of Educational Psychology, 90 (2), 224-235.

Woolfolk, AE (2004). Educational Psychology (9th ed). Boston: Allyn and Bacon.

Wright, T. (1989). Tutorials as a context for developing independence through interaction . Paper presented at the Conference of the International Council for Distance Education and the British Open University Regional Academic Services, Cambridge, England. (pp. 257-263).

Zimmerman, BJ (1998). Developing self-fulfilling cycles of academic regulation: An analysis of exam instructional models. In DH Schunk., \& Zimmerman, BJ (Eds.). Self-regulated learning: From teaching to self-reflective practice. New York: The Guilford Press.

Zimmerman, BJ, \& Schunk, DH (1989). Self-regulated learning and academic achievement Theory, research, and practice . New York: Springer-Verlag. 